\title{
O SENTIDO DA HISTÓRIA DO BRASIL.
}

\section{JOSE HONORIO RODRIGUES}

da Academia Brasileira de Letras.

\section{1. - O SENTIDO DA DESCOBERTA, CONQUISTA, IN- CORPORAÇÃO E INTEGRAÇÃO.}

A visão retrospectiva da história do Brasil nestes 474 anos de sua vida apresenta como primeiro aspecto inconfundivel a durabilidade de seu processo de descoberta e conquista. O Brasil não é um pais descoberto a 22 de abril de 1500 . O processo de descoberta é contínuo nos seus quase cinco séculos de existência. Já no proprio século XVI iam-se ampliando pela costa as descobertas e as conquistas, às vezes pacíficas, mas quase sempre cruentas. Os descobridores e colonos portugueses tinham que enfrentar os índios e os franceses, comerciantes de pau-brasil. Por isso Capistrano de Abreu escreveu que o Brasil nada deve aos espanhois, mas sua história inicial se prende aos franceses, que disputaram vários trechos do litoral aos portugueses.

Todo o desenvolvimento do século XVI se fez percorrendo o litoral, reconhecendo a costa, denominando suas particularidades com o calendário cristão à mão, e ao seu final já havia domínio português, contestado, é verdade, pelos franceses, desde o forte dos Três Reis Magos, no Rio Grande do Norte, até Cananéia, incluindo já São Paulo, no interior. Começava-se a elaborar uma obra imensa de descoberta, de conquista, de povoamento, de pesquisa, para arrancar da terra os seus recursos, de lutas com os índios, de mistura com eles, de contacto sexual, subordinação econômica, predomínio político. Esta era a obra de um século: Itamaracá, Igaraçú, Olinda, Recife, Porto Calvo, São Cristovão, Salvador, Ilheus, Santa Cruz, Porto Seguro, Espírito Santo, Rio de Janeiro, São Vicente, São Paulo, Itanhaem e Cananéia.

Vem o século XVII e o processo continua. O descobrimento da costa leste-oeste, o caminho para o Norte, partindo da Paraiba e de 
Pernambuco, leva os descobridores portugueses ao Ceará, a São Luís, à expulsão dos franceses aí fixados, à fundação de Belem em 1616, e à expulsão de ingleses, franceses e holandeses que se estabeleciam pelo litoral paraense. A penetração amazônica é um feito memoravel. Saindo de Quito e navegando dois anos e oito meses, Francisco de Orellana atingira o Atlântico aos 24 de agosto de 1542. O feito será repetido por Pedro Teixeira em outubro de 1637: largando de Belem vai a Quito e volta a Belem em dezembro de 1639. Pedro Teixeira é um sertanista, um dos maiores, neste século de sertanistas.

O século XVII não é propriamente de descobertas marítimas, exceto para o Sul, pois chega-se a Laguna, que seria o marco do Tratado de Tordesilhas, em 1676, passando por São Francisco em 1658 e Desterro (Florianópolis) em 1675. E o século da conquista do sertão, do bandeirismo, muito mais que da luta contra os holandeses. 0 descobrimento continua e a maior força inata no Brasil é então o bandeirismo, do qual Antônio Raposo Tavares é a maior figura, pois percorre todo o pais, desde Guairá, donde sai em 1648, até a boca do Amazonas em Belem, onde chega em 1651. E um empreendimento tão grande quanto qualquer viagem marítima de circunavegação do mundo, desde a primeira feita pelo português Fernão Magalhães, em 1519-1521. As grandes figuras do bandeirismo constituem por si só uma galeria dos grandes brasileiros que alargaram o território e empreenderam a incorporação, defendendo, na prática, o princípio do uti possidetis, que será utilizado pela diplomacia brasileira na definição de seus limites.

Minas Gerais é descoberta e percorrida nos fins do século XVII, tal como o Piauí. Já então a América Portuguesa vinha do Amazonas à Colônia do Sacramento, no atual Uruguai, pois desde 1680 aí se estabelecera Manoel Lobo.

Com o século XVIII o descobrimento continua. Minas Gerais vai ser pouco a pouco percorrida, descobertas suas riquezas e fundados seus primeiros arraiais. Goiás e Mato Grosso (1718 e 1725) vão sendo incorporados à história do Brasil. Estão abertos os caminhos interiores fluviais ou terrestres entre o Pará e o Maranhão, entre Mato Grosso e o Pará. Por mais precaria que fosse a comunicação, a verdade é que já estavam ligados o Maranhão com a Bahia e Pernambuco, servindo-se do Parnaiba e do São Francisco. No "Roteiro do Maranhão a Goiás pela Capitania do Piauí", de 1800, mostrava-se a enormidade do feito nestes três séculos de descobertas, conquistas, entradas e roteiros.

Deve-se dizer, para maior glória destes homens, que eram na sua maioria gente rude, semi-analfabeta, semi-barbarizada, falando a 
língua geral e não o português. Quando o Bispo de Pernambuco descreveu um deles, Domingos Jorge Velho, como um dos maiores selvagens com quem tinha topado, trazendo com ele um língua (intérprete), porque não falava português, e sete concubinas, afora a mulher com quem casara havia pouco, a única diferença que fazia do mais bárbaro tapuia era o dizer que era cristão. Este retrato caracteriza todos eles, gente rude, violenta, incivil, acostumada à vida dura do campo, que não era mais portuguesa, tivesse ou não nomes limpamente portugueses.

Um dos grandes problemas da política colonial foi achar comunicações, independentes do capricho das moções, e daí os vários roteiros descobertos e descritos. Para realizar a conquista do interior a solução foi o gado vacum, que se transportava ele próprio nas maiores distâncias, dava-se bem em regiões impróprias ao cultivo de certos gêneros, pedia pouco pessoal para vigia-lo e guia-lo, não exigia capitais, fornecia alimentação, vestuário e mobilia, e só carecia de sal. Desde então se estabeleceram grandes latifúndios de criação de gado. O Piauí e o Rio Grande do Sul foram descobertos e conquistados, e iniciado o povoamento por obra desta criação. Não havia nenhuma ordem ou organização pelo interior e somente em 1699 se criaram os primeiros juizes do sertão, saidos dos mais poderosos, pela terra e pelo gado.

Antes dos meados do século XVIII descobriram-se novos caminhos ligando Cuiabá ao Paraguai; Francisco de Melo Palheta ia às aldeias do Mamoré, outros navegavam para o Norte, pelo Guaporé, pelo Tapajós, pelo Madeira, outros para o Sul, pelo São Francisco e o Tietê. A execução do Tratado de Limites de 1750 favoreceu a exploração e o conhecimento de vastas regiões.

No século XIX predominam as viagens e as descobertas de naturalistas, sem que se abandone a busca de caminhos novos, de terras desconhecidas. Basta lembrar que a rápida guerra de 1801 anexa ao Rio Grande do Sul as terras das missões orientais, aquem-Uruguai. Nele, como no século XX, o problema era sobretudo o de comunicações e ocupação efetiva. Durante o Império acreditou-se na navegação fluvial, na de cabotagem e nas estradas de ferro, mas seu legado foi relativamente pequeno: $9.583,087 \mathrm{kms}$. em 1889. A Primeira República limitou-se a construir $22.000 \mathrm{kms}$. de vias férreas. Desde 1926 reduziu-se a construção ferroviária, substituindo-a pela rodoviária. O primeiro plano rodoviário nacional é de 1944, o primeiro fundo de 1945. A discreta evolução rodoviária começa a ser vencida com Getúlio Vargas e especialmente com Juscelino Kubitschek, que foi o maior construtor de rodovias no Brasil até a sua epoca, formando 
uma rede de verdadeira integração nacional, com as grandes rodovias Belo-Horizonte-Brasília, Belo-Horizonte-São Paulo, São Paulo-Brasília, e a Belem-Brasília. Desde então a idéia dominante é a de integração por todos os meios e sistemas: ferroviário, rodoviário, hidroviário, aéreo, portuário e de navegação. O Plano Nacional de Viação de 1964 e o Programa de Integração Nacional de 1970 visam a efetiva ocupação de extensas terras nacionais, com o desbravamento de terras virgens e a abertura de fronteiras novas de desenvolvimento. Neste destacam-se a Transamazônica e a Perimetral do Norte, que cortarão a Amazônia em todos os sentidos, formando o anel amazônico. A Transamazônica, com $1750 \mathrm{kms}$. de extensão, unirá Manaus à rede rodoviária do Nordeste. Aos 16 de dezembro de 1973 o Ministro Andreazza anunciou:

"Está feita a ligação rodoviária entre João Pessoa e Rio Branco. Cinco mil quilômetros de estrada já cortam transversalmente toda a floresta amazônica".

A ligação de Cuiabá a Santarem, a pavimentação da Belem-Brasília, e a Perimetral do Norte, iniciada em 1973, que atravessa os Estados do Pará, Amazonas e Acre, e os Territórios do Amapá e Roraima, estendendo-se por $4.125 \mathrm{kms}$., revelam um programa de ligação e intercomunicação que tenta atender à grande aspiração nacional de ocupação efetiva, de nacionalização de todo o território. $\mathbf{O}$ sentido da história do Brasil de descobrimento, conquista, ocupação efetiva, integração nacional, vem do primeiro século e continua vivo e atuante neste, tudo fazendo crer que o seguinte verá bem avançado este ideal, que não se limita a comunicar, mas mantem desperta a idéia de descobrir, de descobrir sempre novas terras, novos recursos, novas riquezas.

\section{2. - A NATUREZA E SUA TRANSFORMAÇÃO.}

A natureza e a geografia são o substrato da história; as condições geográficas não têm poder criador, mas são parte influente. Nesta imensa extensão territorial da natureza brasileira, em latitude e longitude, diversidades orográficas, climáticas, variedades de origem e idade geológica, nesta zona tropical se abrigavam varias regiões naturais consideradas hostis ao homem branco ocidental, que com o tempo histórico vão ser transformadas. Tudo parecia conspirar contra uma possivel futura unidade política, pelas grandes diferenças de região para região, e sobretudo nos primeiros tempos a correlação entre a na:ureza nova, a flora, a fauna e o nativo. 
Para criar-se o Brasil como unidade era necessário, sob pena de extermínio, adaptar-se ao meio. A força da ação mesológica foi muito mais poderosa no começo do que é hoje. Os perigos que se corriam dos animais bravos, de inimigos, os calores excessivos, a novidade da flora, inteiramente diferente, e da fauna, tudo concorria para que o homem acabado de chegar fosse submetido ao tremendo processo de adaptação. Com pouco tempo os portugueses conheceram o valor das plantas nativas, as que se comiam, as virtuosas ou medicinais e as venenosas. Adaptaram-nas em sua cozinha e uso, e levaram algumas para a Europa, África e Ásia, e de lá trouxeram o que acreditaram ser util às suas colônias.

As plantas mais importantes encontradas no Brasil foram a mandioca, o milho, a batata comum e a doce, várias espécies de feijão, ananazes e abacaxis, espécies de bananas, o mamão, o cajú, a jaboticaba, a mangaba. Tudo o mais veio de Portugal, da Espanha, da África e da India. Do Reino vieram o melão, o figo, a uva, o limão e a laranja. Da Madeira, a cana de açucar. Arábico era o café, da China o chá. Do Reino vieram ainda a melancia, o nabo, a couve, a alface, alhos, agrião, beringela. Da India vieram a pimenta, o coco, a jaca, a noz, a manga, o tamarindo. Das Ilhas do Cabo Verde veiu o arroz, embora existisse uma espécie nativa. A vinda, na segunda metade do século XVIII, de plantas, frutos e árvores, coqueiro, palmeira, amendoeira, modificou a paisagem e hábitos alimentares. Esta troca de plantas e frutos serviu no Brasil para adaptar o europeu e o africano ao novo ambiente natural.

Para que esta adaptação se efetuasse de forma valiosa era necessário a aiuda do elemento nativo, e foram os índios os guias, os veículos que auxiliaram a dissolução do elemento afro-português. Porque se os índios não tinham vencido a natureza, antes tinham sido por ela subjugados, conheciam na carne e no espírito as influências sensíveis naturais. Nenhuma transformação se faria sem eles. Eram vencidos pela natureza e seriam vencidos pelos portugueses, mas os vencidos inoculam sempre nos vencedores germens tão fortes que a síntese nova, o novo homem, contem em si os fatores necessários à sobrevivência e, com o tempo, a força para transformar a natureza e po-la a seu serviço. Para essa transformação concorreu tambem a introdução pelos europeus de todos os animais domésticos.

Toda a América do Sul, concorreu no inventário internacional dos animais domésticos apenas com um único, o pato. Tudo o mais veiu do Reino e das Ilhas, e daí a tese da inferioridade da América na fauna, que começa com Buffon. A exceção é ornitológica, possuindo o Brasil um sexto de todas as espécies de aves do globo. Nem um tipo 
de mamífero terrestre superior teve aqui sua origem, excetuada a onça pintada, a anta, o veado, a capivara, o tamanduá bandeira, o tatú-canastra. A natureza era hostil ao branco europeu português, como o era ao africano, acostumados a outros ambientes.

A história do Brasil tem, portanto, este sentido singular. A natureza em que se elaborou seu processo civilizatório esteve sempre em constante luta contra os vencedores políticos, e se não fossem os vencidos, a natureza poderia te-los destruido. Este processo contínuo de transformação é duradouro; é mais forte nos dois primeiros séculos, mas continua no XVIII, XIX e XX. Os naturalistas do século XVIII, especialmente Alexandre Rodrigues Ferreira, e os viajantes, botânicos e zoólogos do século XIX trazem ao processo da história do Brasil uma contribuição importante ao ensinar como sobreviver, como viver e como por a natureza a serviço do mestiço, um produto especial que o Brasil fabricou no seu processo de adaptação histórica da natureza e da gente.

Este processo evolutivo e histórico de ligação harmônica entre o homem e a natureza, os vários homens e as várias naturezas, como é o caso brasileiro, revela como se forma um modo de viver e de costumes inteiramente adaptado ao ambiente e como este tambem se modifica pela ação do homem. A Amazônia serve de exemplo atual ao que foi este sentido de ação e reação entre a natureza e a história, na evolução do Brasil. Hans Bluntschli, no seu $A$ Amazônia como Organismo Harmônico (Manaus, s. d.), notou como no Brasil e especialmente na Amazônia

"os fatores que compōem a natureza agem em conjunto e correspondem um ao outro, criando uma verdadeira unidade, da qual nem o homem amazônico é excluido".

Quando ele escreveu em 1912, com uma compreensão de todo, da magnitude e unicidade orgânica da natureza, da notavel uniformidade do tipo de flora e fauna de toda a Amazônia, queria sustentar que aquele todo constituia

\footnotetext{
"um organismo harmônico com vida própria, nitidamente estampada".
}

O reino animal era rico, a floresta de uma grandeza infinita e só era pobre de gente, a densidade extremamente reduzida do humano. Pois esta região maravilhosa e harmônica já perdeu 843 mil quilômetros quadrados, ou seja $24 \%$ de suas florestas, que hoje cobrem uma 
área equivalente a $32,08 \%$ da superfície total do território nacional. A devastação da floresta amazônica, que as rodovias planejadas e construidas aumentam, se agrava com a destruição florestal no Nordeste, no Sudeste do Sul e no Centro-Ooeste.

A natureza brasileira continua sua evolução histórica, acompanhando a fabricação de sua história humana e concorrendo para dar ao conjunto um sentido próprio.

\section{3. - O SENTIDO HUMANO.}

A humanidade brasileira se constituiu de três elementos capitais, um nativo e dois exóticos. O nativo se dividia numa multidão de tribos diferentes, avaliada em um milhão e quinhentos mil na época da descoberta. Eles estavam num grau cultural muito atrazado, especialmente comparados a outros grupos indígenas da América, no Perú, México e Guatemala. Desde o começo oferecem resistência, mas acabaram sendo vencidos. Uns aceitaram a subjugação, misturaram-se, ajudaram os invasores de suas terras; outros não cederam, fugindo para outras regiões no litoral ou no interior, ou morreram lutando. As guerras indígenas duraram até hoje, oficiais ou particulares, mas nos primeiros séculos a população indígena foi dizimada pelas guerras e pelas epidemias. A Guerra dos Bárbaros (1683-1710) não derrota a resistência armada, embora destruindo milhares de índios; as guerras oficiais ainda existem com D. João VI e com D. Pedro I. Segregados em aldeias, durante muito tempo, foi possivel a muitos acomodarem-se aos vitoriosos, misturarem-se e produzirem as várias formas de cabloclos e mestiços que dominam a grande população brasileira. O papel dos índios como o dos negros, no Brasil, foi semelhante ao dos bárbaros no mundo romano. Os vestígios de sua influência não se limitam ao enriquecimento vocabular, aos costumes sociais, aos habitos alimentares; pode-se mesmo escrever que muitas diferenças regionais no aspecto físico, na prosódia da língua corrente se devem às diferenças entre os grupos raciais negros ou índios que compõem a mistura. Os grupos indígenas que mais se misturaram foram os tupi e os carirí, e os sudaneses e bantos entre os africanos. Deve-se levar em conta tambem os grupos regionais portugueses que participaram da mestiçagem e deram à sua composição elementos diferenciais. A mestiçagem e o crescimento autônomo da população brasileira são seus dois aspectos fundamentais.

Durante o período colonial - três séculos — as ondas imigratórias portuguesas eram facilitadas ou dificultadas por uma legislação espacial. A maior corrente deu-se na época da descoberta das Minas 
Gerais, entre 1696 e 1760, quando uma aluvião de portugueses buscou enriquecer-se com o ouro e os diamantes e ocorreu uma grande introdução de escravos. Calcula-se em um milhão e quinhentos mil o número de negros entrados desde mil quinhentos e quarenta e poucos até 1850 .

Esta composição populacional dominou a história brasileira durante os três séculos coloniais. Desde 1808 começa uma nova introdução de elemento branco, portugueses $(16.000 \mathrm{com} \mathrm{D}$. João VI e mais até a Independência) e de grupos pequenos de ingleses, franceses, alemães e espanhois. A partir de 1820 começam a ser fundadas as colônias de imigrantes, grupos inteiros de famílias contratadas por um agente e com facilidades criadas pelo Governo. A primeira é Friburgo, em 1820, constituida de colonos suiços; a segunda é São Leopoldo, em 1824, composta de alemães; seguem-se várias que fracassaram, voltando muitos para sua terra natal ou outros lugares, ou vindo para as cidades. Outras colônias sobreviveram, como Petrópolis, Blumenau, Joinville, Caxias, Brusque, etc.

A verdade é que dos 5 milhões de imigrantes entrados no Brasil entre 1820 e $1950,1.400$ mil voltaram aos seus paises. Por isso se podia concluir em 1961 que a contribuição do imigrante para o aumento da população foi bem menor do que geralmente se supõe. $O$ crescimento da população se deve ao nivel muito mais elevado da natalidade que a mortalidade. As maiores correntes foram a dos italianos e portugueses, seguidos dos espanhois, alemães e japoneses. As maiores imigrações de estrangeiros ocorreram nos últimos lustros do século passado e no início do XX, e têm decrescido nestas últimas décadas, pois a própria Europa rica absorve a mão-de-obra barata dos paises pobres. Ainda assim nenhum pais recebeu tantos imigrantes japoneses, e somente os Estados Unidos acolheram maior número de alemães; poucos paises receberam tantos italianos, e somente a Argentina e o México possuem maior número de espanhois, ou somente a Argentina e Cuba, de galegos. Outros contingentes de sírios, eslavos, armênios, austríacos, chineses, holandeses, poloneses, ucranianos, contribuiram para aumentar a composição variada da nossa etnia. Sua distribuição territorial está concentrada no Sul, e São Paulo, Rio Grande do Sul, Paraná e Santa Catarina possuem a grande maioria.

A entrada de imigrantes cai ano a ano e entre 1962-1971 passou o total de 31.138 para 6.378 . Em 1940, este contingente era de $3 \%$ da população total; em 1950 a proporção caiu para $2 \%$ e hoje deve representar uma relação ainda menor. $O$ Censo Demográfico (1970) avalia para uma população total de $92.139 .037,166.383$ naturalizados e 1.082 .745 de estrangeiros. Por isso se pode dizer com 
toda confiança que a personalidade básica brasileira permanceu própria e singular, e as alterações que vem sofrendo ao longo do processo histórico não se devem aos naturalizados ou estrangeiros. $O$ único fato novo é a presença cada vez maior dos descendentes dos imigrantes na vida pública brasileira, e não só os de várias gerações, como seriam os de Friburgo e São Leopoldo, por exemplo, mas os de primeira geração. As qualidades e defeitos da gente brasileira não podem ser retratados num quadro simplista. Sua variação de comportamento se vê na história, ora omisso, ora participante, uma vez pacífico, outra violento, cruento ou incruento, paciente e submisso, consentindo mais nas soluções de que não participa, que a elas se opondo, sempre derrotado política e economicamente.

\section{4. - O SENTIDO CULTURAL-EDUCATIVO E SANITA- RIO.}

Toda a história do Brasil é extremamente negativa no sentido cultural. Não seria justo, 150 anos depois da Independência, recriminar o período colonial português (322 anos) como responsavel pelo alto índice de analfabetismo, de incultura, de insalubridade que dominou a história do Brasil. O legado português é calamitoso, mas o período nacional, imperial ou republicano é igualmente funesto. Antônio Vieira escreveu em 1640 que

\footnotetext{
" "não sei qual the fez sempre maior mal ao Brasil, se a enfermidade, se as trevas".
}

O povo brasileiro continuou vivendo nas enfermidades e nas trevas, e os resultados continuam negativos.

Desde a Independência pensou-se em uma Universidade, e criaram-se no ensino superior apenas faculdades de direito, medicina e engenharia. A primeira Universidade Federal é de 1939. Recursos para educação e saude foram sempre modestos, e o Império e a República deixaram as duas entregues aos cuidados do Ministério do Império e da Justiça até 1930, quando foi criado o Ministério da Educação e Saude, desdobrado em 1953 com a criação do Ministério da Saude, transformando-se o primeiro em Ministério da Educação e Cultura. Apesar de uma melhor atenção para estes dois problemas fundamentais, o orçamento da educação é proporcionalmente cada vez menor. Sua participação no orçamento federal caiu de $9,74 \%$ em 1964 para 4,95\% em 1974. O orçamento dos Transportes (Cr\$ $6.709 .445,000,00)$ é quase três vezes o da Educação $(\mathrm{Cr} \$ \ldots$ 
2.901.332.900,00) e as três forças armadas (Exército, ....... 3.798.183.000,00; Aeronáutica, Cr\$ 2.294.871.800,00; e Marinha, Cr\$2.109.326.200,00) somam uma quantia muito alta (Cr\$ 8.202.380.000,00) para uma nação em desenvolvimento, com um povo pobre e doente, cujo acesso ao ensino não atinge a $30 \%$ da população em idade escolar. O Ministério da Saude tem um orçamento absolutamente inferior às suas necessidades .

Apesar da saude, tal como a educação, figurar entre os componentes básicos de um processo de desenvolvimento, o Brasil continua sua tradição de cuidar pouco e mal da saude popular. Segundo o Ministério, $76 \%$ do povo vive subalimentado, a mortalidade infantil em São Paulo tem hoje taxa superior à de 20 anos atrás, as doenças transmissíveis continuam a fazer $40 \%$ das mortes, a pobreza e a falta de higiene aumentam as endemias no Brasil. O quadro vexatório se enegreceu nestes dez últimos anos de empobrecimento popular e enriquecimento dos ricos e das empresas estrangeiras. A evolução histórica permanece a mesma: a continua desatenção pela saude e pela educação popular.

Os valores culturais populares permanecem vivos e são estimulados pelos orgãos de comunicação de massa, com o auxílio do governo, que neles vê uma forma efetiva de não participação política. Está assim a cultura brasileira diante de uma formidavel contradição. Os valores populares, a música, as crenças sincréticas, os esportes em geral, o futebol em particular, o carnaval são favorecidos, enquanto se cuida menos da educação e da saude populares.

A única grande vitória cultural popular, ao longo do processo historico, foi o uso generalizado do português, vencedor na luta contra as várias línguas indígenas e negras que ameaçaram a unidade linguística brasileira. Quando se pensa que até a segunda metade do século XVIII em São Paulo, no Amazonas, e em outras partes interiores do Brasil falava-se mais a língua geral que a portuguesa, não se pode deixar de reconhecer que esta foi uma grande vitória popular, pois o povo teve de aprender sozinho, ouvindo, reagindo e recriando uma língua básica corrente. Ainda que se estabeleçam os três níveis da modalidade falada - a vulgar, a coloquial corrente e a culta (Adriano da Gama Kury, $A$ estrutura movel da realidade linguística, "Jornal do Brasil", 6 de outubro de 1973) -, é a vulgar a língua dominante no Brasil, ignorando-se qualquer disciplina gramatical. Apesar disso, a unidade se mantem, embora reflita um desnivel sócio-econômico incapaz de romper a comunicação entre todos os grupos sociais, como existe em outros paises de tamanho minúsculo ou continental. As formas culturais como o romance, a poesia, o ensaio, a 
história são na sua grande maioria elitistas, inacessíveis ao povo, escritas por uma minoria branca que não consegue comunicar-se com uma maioria mestiça na cor e na cultura.

\section{5. - O SENTIDO ECONOMMICO.}

$\mathrm{Na}$ evolução brasileira nossa economia esteve sempre voltada para fora, buscando satisfazer com gêneros primários as necessidades do mercado internacional. Não há história de ciclos econômicos de limites definidos no tempo, pois ou coincidem mais de dois produtos, ou se sucedem na importância da exportação. Nunca se criou um mercado interno, e desde o período colonial o povo escravo e não o branco livre foi quem mais trabalhou e quem pouco pode fazer para sobreviver. Os níveis de vida de um escravo ficaram sempre entre 10 e 15 anos, de sua introdução à sua morte. E a escravidão durou praticamente quatro séculos. Esperanças de melhoria animaram sempre o povo brasileiro, mas ele foi sempre economicamente um povo derrotado. Derrotado duplamente, como indivíduo, pela extrema pobreza de sua vida própria, e como povo, como participante de uma riqueza nacional. Passamos 322 anos trabalhando para Portugal; depois, grande parte da riqueza nacional vem sendo espoliada pelo estrangeiro, não só através dos capitais investidos e suas consequências, como pelos preços pagos pelo trabalho nacional. Cada vez exporta-se mais e recebe-se relativamente menos.

Dificilmente se reconheceu, como fez Heinrich Handelmann na sua História do Brasil,

"que ao contrário dos Estados Unidos aqui um povo trabalhou quase sem auxílio estrangeiro algum, na obra da civilização".

E assim como esse grande historiador alemão reconheceu o esforço do povo brasileiro na construção do Brasil, assim o financista inglês J. P. Willem (The Braziliam Exchange, 1896), examinando a economia brasileira de 1860 a 1894 não hesitou em escrever que os recursos nacionais, quase desassistidos de qualquer auxílio estrangeiro, foram suficientes para empreender a recuperação econômica logo após a guerra do Paraguai, elevando o índice do câmbio do seu mais baixo ponto a uma posição acima do par (1868-1875) .

O povo brasileiro pagou pacientemente imensas somas de dívidas para alcançar a mesma posição, da qual fora rebaixado pelos desmandos das classes dominantes. Ao esforço do povo e ao emprego de capital nacional se deveu a recuperação. 
"Nosso país é uma feitoria colonial",

escrevia um parecer da Câmara, denominado magistral por Rui Barbosa e por ele transcrito, em parte, no seu Relatório do Ministério da Fazenda (1891).

O sentido da história do Brasil do ponto de vista econômico tem sido sempre não o de liberta-lo da subordinação ao capital estrangeiro, mas mante-lo como um pais ao serviço das grandes potências. As tentativas de libertação econômica, pela criação de um grande mercado próprio, a elevação da renda individual, da melhoria geral do padrão econômico do povo brasileiro foram sempre derrotadas, ainda quando se apresentaram em forma pacífica.

\section{6. - O SENTIDO POLITICO.}

O processo histórico brasileiro revelou sempre um profundo distanciamento entre as classes dominantes e o povo. Durante todo o período colonial a separação entre os representantes do governo colonial e os mazombos, escravos, mestiços de todas as cores foi muito grande. Os interesses metropolitanos e os dos colonos sempre divergiram. Contribuiram ainda para agravar esta diferença as lutas sangrentas primeiro com os índios, exterminados em massa e mortos por doenças e fomes. As rebeliões africanas deram maior gravidade aos problemas das relações raciais e sociais.

Se a história do Brasil não é uma história francamente cruenta, é impossivel negar o carater sangrento com que se processou muitas vezes o domínio das grandes massas escravas ou escravizadas. Deve-se contar ainda as grandes fomes, as grandes epidemias, e as endemias que grassaram sempre e tornaram ensanguentado o processo histórico brasileiro. A linha conciliatória ocorreu muitas vezes e moderou a violência do processo; outras vezes, a submissão, a paciência, a omissão de um lado, e o temor, a necessidade e o poder promoveram os acordos tácitos que não diminuem as distâncias, mas permitem baixar as tensões sociais, evitar os conflitos e praticamente conseguir um consenso provisório.

No Brasil, nenhuma revolução foi jamais vitoriosa. Houve rebeliões populares e sociais, como a balaiada, a cabanagem, a praieira; houve banditismo social, rebeliões negras; houve Canudos, o Contestado, mas sempre foram movimentos esmagados e os vencidos nunca puderam obter dos vencedores senão pequenas concessões. As rebeliões das classes dominantes, como a liberal de 1841, os Farrapos de 
1835-1845, levaram o Poder a fazer concessões de carater político. O Poder, como um círculo de ferro, estendia-se para permitir que um ou outro lider revelado pelo outro lado, no mesmo nivel social, entrasse para o grupo dominante. Foram essas liberdades de trânsito político, foram as tolerâncias, foram as pequenas doações aos grupos sociais maiores e mais cheios de reivindicações que permitiram uma relativa paz durante alguns períodos da história brasileira, mais no Império que na República. A conciliação foi o grande instrumento político, tal como a moderação, e nisso se distinguiram fluminenses, mineiros e baianos, os políticos que tiveram sempre diante de si, cheias de queixas e aspirações, as massas negras, as mais sofridas de todas.

A evolução política revela, assim, consenso e omissão, proibição e rebeldia, liberdade e tolerância, sempre sob o domínio da conciliação política e social. Quando a inconciliação dominou, como houve fases na época colonial, imperial e republicana, houve tanto a submissão como a omissão, a brutalidade como a rebelião, e a história se pacificou ou se ensanguentou.

As fases criadoras foram sempre as da colaboração mais íntima e estreita, as da compreensão maior entre a liderança e o povo. $\mathrm{Na}$ história política brasileira houve sempre da parte da liderança o temor e o desapreço ao povo e da parte deste a omissão e o medo. Os ensaios absolutistas, sempre recolonizadores, foram de pouca duração no Brasil; D. Pedro I fez um, de curto tempo; Floriano, outro, de carater brutal e sangrento, mas tambem de breve período. Assim foram os mais modernos, como Getúlio Vargas e os mais recentes. A inflexibilidade e a inconciliação parecem normas políticas atuais. Elas podem fechar as portas do entendimento. O povo brasileiro, pela sua mestiçagem, é mais brando e tolerante; é mais homogêneo, comparativamente, que muitos outros povos, apesar da diversidade de etnias, culturas e origens de sua atual composição. Sua tendência, de acordo com a sua história, é para um entendimento político que abra o diálogo entre as várias classes, promova a ascensão social, melhore a situação econômico-social da grande maioria. No Brasil, o problema social nunca foi o dos direitos das minorias, mas o dos direitos da maioria.

O Brasil não tem graves problemas minoritários. O grande problema brasileiro é o da sua maioria, vilipendiada, tutelada, roubada. O verdadeiro sentido da história do Brasil é a conquista dos direitos da maioria. Enfim, como escreveu Capistrano de Abreu, o povo foi capado e recapado, sangrado e ressangrado. 
JOSE HONÓRIO RODRIGUES. - E um dos historiadores brasileiros da atualidade que mais contribuiram para a ampliação e renovação dos estudos históricos no Brasil.

Nascido no Rio de Janeiro em 1913, iniciou sua carreira ganhando o Prêmio de Erudição da Academia Brasileira de Letras em 1938.

Cabe-lhe o indiscutivel mérito de, em qualquer cargo exercido, ter revitalizado e valorizado a função de historiador, como fez no Instituto Rio Branco, na Secção de Obras Raras e Publicações da Biblioteca Nacional e no Arquivo Nacional.

Alem de professor e conferencista é um fecundo escritor, cuja obra é de conhecimento obrigatório de todos os estudiosos da História do Brasil. (Nota de Raquel Glezer). 